\title{
Clinical Relevance of T1-S, an Oncogene-Inducible, Secreted Glycoprotein of the Immunoglobulin Superfamily, in Node-Negative Breast Cancer
}

\author{
Dieter Prechtel, Nadia Harbeck, Ursula Berger, Heinz Höfler, and \\ Ann Katrin Werenskiold \\ Institut für Allgemeine Pathologie und Pathologische Anatomie (DP, HH, AKW), Frauenklinik (NH), and Institut für \\ Epidemiologie und Statistik der Technischen Universität München (UB), Munich, Germany
}

SUMMARY: Axillary lymph node-negative breast cancer patients have a low risk for disease recurrence, and the majority of these patients are cured by surgery alone. However, accurate identification of that $30 \%$ of node-negative patients who are at high-risk for relapse and who might therefore benefit from adjuvant systemic therapy has not been possible using traditional histomorphological and clinical prognostic factors alone. Identification of novel tumor-associated molecules may therefore provide a basis for a better understanding of and eventually for an interference with disease progression. We have recently reported on tumor-associated RNA up-regulation of the secreted, soluble T1-S receptor in node-negative breast cancer. In the present study we analyzed the tumor-associated level of the T1-S receptor using semiquantitative immunohistochemistry in a collective of 102 node-negative breast carcinomas to study its clinical relevance. A high T1-S immunoreactivity score indicating T1-S overexpression was observed in 58 of $102(57 \%)$ cases. The T1-S score was independent of the tumor size, type, grade, steroid hormone receptor status, and the proliferation rate determined by monoclonal antibody against KI-67 protein (MIB1) immunohistochemistry. In univariate and multivariate analysis of disease-free survival, a high T1-S score $(p=0.003)$ and a low MIB1 score $(p=0.001)$ were the only parameters that were highly significantly associated with an improved disease-free survival period. We conclude that T1-S receptor overexpression is a novel and independent tumor biological factor that may be associated with reduced progression of lymph node-negative breast cancer. (Lab Invest 2001, 81:159-165).

$B$ reast cancer is the most common malignancy in women in the Western world. More than $10 \%$ of women develop this disease during their lifetime (American Cancer Society, 1994), and more than half of them will eventually die from the disease. Because of an increase in the early detection of breast cancer, the number of axillary node-negative patients is still increasing. Axillary lymph node involvement is presently the strongest factor available for the assessment of patient prognosis (Merkel and Osborne, 1989). Node-negative breast cancer patients have a rather low risk of relapse compared with node-positive patients. Approximately $70 \%$ of the node-negative patients are cured by surgery alone and therefore do not require adjuvant systemic therapy. Only $30 \%$ of nodenegative patients will relapse within 10 years after surgery and eventually die of metastasis (Clark and McGuire, 1988). Traditional histomorphological and clinical factors (tumor size, grade, type, steroid hormone receptor status, age, and menopausal status)

Received August 31, 2000.

This work was supported by Deutsche Krebshilfe (grant 10-1380 WeI) and in part by a grant from the State of Bavariato N.H. (KKF Project \#8756159).

Address reprint requests to: Dr. Dieter Prechtel, Institut für Allgemeine Pathologie und Pathologische Anatomie, Klinikum rechts der Isar, Technische Universität München, Ismaningerstr.22, 81675 Munich, Germany.E-Mail:prechtel@lrz.tum.de do not reliably identify those node-negative patients at high risk for disease recurrence who might benefit from adjuvant systemic therapy. Using conventional prognostic factors, more than $75 \%$ of all nodenegative breast cancer patients receive adjuvant systemic therapy, even though only about 30\% will eventually develop systemic disease (McGuire and Clark, 1992). Recent research has therefore aimed at elucidation of early events in tumor progression that are linked to tumor aggressiveness. Tumor-related alterations in cell cycle regulation and growth factor receptor signaling, which appear to be involved in the progression of lymph node-negative breast cancer to a systemic metastatic disease, have been identified (DeMichele and Weber, 1997; Hoskins and Weber, 1995; Werenskiold et al, 2000). Molecules with tumorrelated alterations, such as the tumor suppressor gene p53 (Silvestrini et al, 1996; Soong et al, 1997) and cyclin E and p27/kip1 (Porter et al, 1997), may also be linked to prognosis in lymph node-negative breast cancer.

The extracellular soluble T1-S receptor represents such a novel tumor-associated molecule that is overexpressed in node-negative breast cancer as we have recently shown (Werenskiold et al, 2000). The T1-S receptor was originally identified as an oncogeneinducible molecule of mouse fibroblasts (Klemenz et al, 1989). The homologues of the T1-S receptor in rat (fit-1-S) (Bergers et al, 1994) and man (ST2) (Tominaga 
et al, 1992) show a high evolutionary conservation; the 328 amino acid human T1-S/ST2 peptide is $67.6 \%$ and $63.5 \%$ homologous to the mouse and rat proteins, respectively. The soluble T1-S receptor is a truncated, secreted variant of a membrane-associated T1 receptor (ST2L/fit-1-M). The sequence similarity of its cytoplasmic portion identifies the T1-receptor as a member of the interleukin-1-receptor/Toll-receptor family (Tominaga et al, 1992). T1 protein variants are encoded by differentially spliced mRNAs. Two major T1 transcripts corresponding to the membraneassociated and soluble T1 protein variants are expressed in mouse and rat tissues, whereas three T1 transcripts have been identified in human cells (Kumar et al, 1997). Human T1 has not been analyzed in detail so far, but extensive work in the murine system showed a tissue-specific differential expression of T1 receptor variants. The membrane-associated $\mathrm{T} 1$ receptor is constitutively expressed in hemopoietic cells (Thomassen et al, 1995) and appears to be associated with Th2 helper cell functions (Lohning et al, 1998; Xu et al, 1998). By contrast, T1-S synthesis is restricted to a few differentiating mouse tissues (Rössler et al, 1995), and an aberrant re-expression of T1-S mRNA was demonstrated in invasive mammary adenocarcinomas of $\mathrm{H}$-ras(EJ) oncogene-transgenic mice (Rössler et al, 1993).

In a small pilot study we recently demonstrated for the first time an overexpression of T1-S mRNA in node-negative human breast cancer cases and showed a correlation of tumor-associated T1-S mRNA levels with the immunohistochemical presence of T1-S protein (Werenskiold et al, 2000).

In the present study, we used immunohistochemistry to assess the clinical relevance of T1-S receptor overexpression in a collective of 102 node-negative breast cancer patients. We demonstrate (a) that the level of tumor-associated T1-S immunoreactivity is independent of established clinical and histomorphological parameters and (b) that high T1-S immunoreactivity is significantly associated with an improved disease-free survival (DFS).

The prognostic impact of $\mathrm{T} 1$ was evaluated in a collective of node-negative breast cancer patients where the majority of patients did not receive any adjuvant systemic therapy. After first relapse, systemic therapy tends to be quite heterogeneous. To study the impact of the factors on the natural course of the disease without the influence of systemic treatment, we therefore focused on disease-free (DFS) and not overall survival (OS).

\section{Results}

T1-S immunoreactivity was determined using two different antibodies: a polyclonal antibody that was obtained against a peptide specific for the T1-S protein isoform (Rössler et al, 1995) and a monoclonal antibody raised against recombinant human T1-S FC protein and, therefore, one that cross-reacts with the membrane-associated T1 receptor (unpublished ob- servations). The T1-S scores obtained with the two antibodies showed a high correlation ( $r=0.86$ Spearman rank correlation coefficient). Minor variations in T1-S immunoreactivity can be attributed to the abovementioned differences in antibody specificity. Because of its specificity for T1-S, only results obtained with the polyclonal antiserum are shown here.

\section{Expression of T1-S in Normal Breast Tissue and Fibrocystic Disease}

In the samples of resting normal adult breast tissue $(n=7)$ and cases of fibrocystic disease $(n=8)$, both T1-specific antibodies displayed a low-to-moderate cytoplasmic T1-S expression (score: 1-6) in the mammary epithelium. The intensity of T1-S immunoreactivity differed in individual cases among different areas and also among individual adjacent cells. The inner epithelial layer of ductal epithelium exhibited higher levels of T1-S immunoreactivity than the outer myoepithelial layer. The denser interlobular stroma showed a higher extracellular T1-S immunoreactivity than the loose fibrovascular intralobular stroma.

The following benign epithelial changes showed a higher level of T1-S immunoreactivity than normal epithelium: metaplastic epithelial change (ie, apocrine metaplasia), distortion of pre-existing glandular components (ie, cystic change), increased number of glandular components (ie, adenosis), and increased number of epithelial cells within pre-existing glandular components (ie, epithelial hyperplasia).

\section{Expression of T1-S in Node-Negative Invasive Breast Cancer}

Both T1-specific antibodies gave a cytoplasmic staining in the tumor cells. Of 102 primary breast carcinomas analyzed, 100 displayed T1-S reactivity in tumor cells at highly variable levels (Fig. 1). The percentage of stained tumor cells within the tumor tissue ranged from $5 \%$ to $95 \%$. Heterogeneity of the staining pattern in different areas was also observed within individual tumor specimens. In ductal carcinomas, tumor cells growing in solid or tubular arrays frequently displayed a higher T1-S reactivity than disseminated single tumor cells. About $50 \%$ of the tumors that exhibited high levels of T1-S immunoreactivity in the tumor cells also showed considerable T1-S reactivity in the stroma. In 14 lobular carcinomas and 9 carcinomas of special histological type (eg, medullar carcinoma), tumor cells displayed a low-to-intermediate T1-S immunoreactivity (score: 1-8). High T1-S immunoreactivity (score: $9-12$ ) was observed only in ductal carcinomas ( $n=$ 16). Extracellular T1-S immunoreactivity did not differ between ductal carcinoma and other types of carcinoma. Two ductal carcinomas lacked any detectable T1-S immunohistochemical reactivity (score: 0), although they did react with other antisera (eg, hormone receptors).

Table 1 shows patient and tumor characteristics and their correlation with T1-S. The level of T1-S 


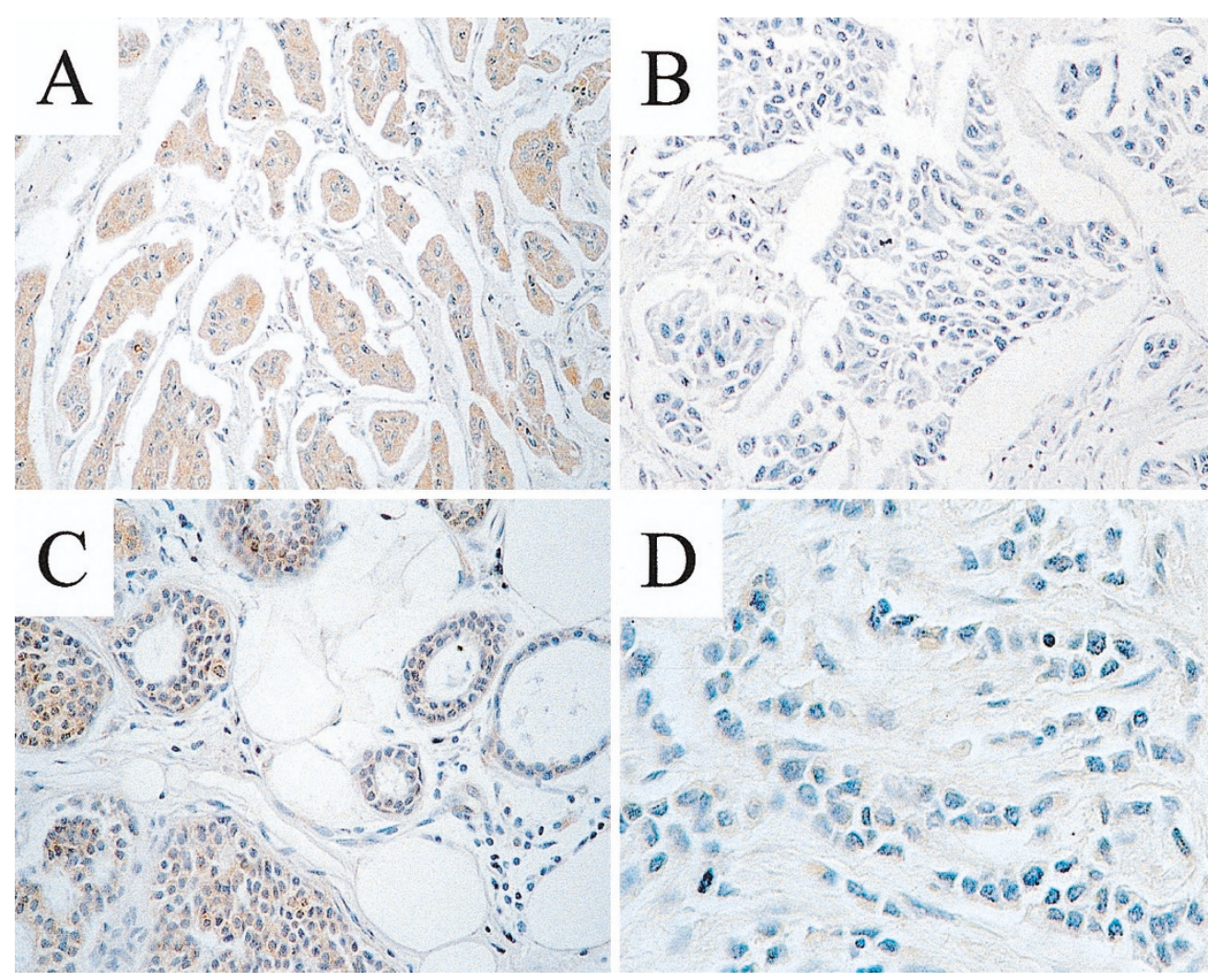

Figure 1.

T1-S immunoreactivity in node-negative breast cancer. Immunostaining of paraffin sections with the polyclonal anti-T1-S antiserum reveals (A) maximal T1-S immunoreactivity (score: 12) in one ductal carcinoma (G3, pT1c, hormone receptor-positive, no relapse after $65 \mathrm{mo}$ ); (B) complete absence of reactivity (score: 0 ) in another ductal carcinoma (G3, pT2, hormone receptor-positive, relapse after $45 \mathrm{mo}$ ); (C) intermediate T1-S immunoreactivity (score: 8) in a tubular carcinoma (G1, pT1a, hormone receptor-positive, no relapse after 80 mo); and (D) low T1-S immunoreactivity (score: 3) in a lobular carcinoma (G2, pT2, hormone receptor-positive, relapse after $22 \mathrm{mo}$ ). Original magnifications: $\mathrm{A}, \mathrm{B}, \mathrm{C}, \times 100 ; \mathrm{D}, \times 200$.

Table 1. Patient and Tumor Characteristics

\begin{tabular}{|c|c|c|c|c|c|c|}
\hline \multirow{3}{*}{ Factor } & \multirow{3}{*}{$\begin{array}{l}\text { Groups } \\
\text { All cases }\end{array}$} & \multirow{3}{*}{$\begin{array}{c}\mathrm{n}^{a} \\
102\end{array}$} & \multirow{3}{*}{$\begin{array}{c}\% \\
100\end{array}$} & \multicolumn{2}{|c|}{ T1-S } & \multirow{3}{*}{$\begin{array}{l}\text { Pearson } \chi^{2} \\
p \text {-value }\end{array}$} \\
\hline & & & & $\leq 4$ & $>4$ & \\
\hline & & & & 44 & 58 & \\
\hline \multirow{2}{*}{ Age } & $\leq 60 \mathrm{yr}$ & 57 & 55.9 & 23 & 34 & NS \\
\hline & $>60 \mathrm{yr}$ & 45 & 44.1 & 21 & 24 & \\
\hline \multirow[t]{2}{*}{ ER } & Negative & 22 & 21.6 & 9 & 13 & NS \\
\hline & Positive & 80 & 78.4 & 35 & 45 & \\
\hline \multirow[t]{2}{*}{$\mathrm{PgR}$} & Negative & 30 & 29.4 & 14 & 16 & NS \\
\hline & Positive & 72 & 70.6 & 30 & 42 & \\
\hline \multirow[t]{2}{*}{ Tumor size } & $\leq 2 \mathrm{~cm}$ & 44 & 43.1 & 17 & 27 & NS \\
\hline & $>2 \mathrm{~cm}$ & 58 & 56.9 & 27 & 31 & \\
\hline \multirow[t]{3}{*}{ Tumor type } & Ductal & 79 & 77.5 & 32 & 47 & NS \\
\hline & Lobular & 14 & 13.7 & 7 & 7 & \\
\hline & Other & 9 & 8.8 & 5 & 4 & \\
\hline \multirow{2}{*}{ Tumor grade } & $\mathrm{G} 1+\mathrm{G} 2$ & 62 & 60.8 & 25 & 37 & NS \\
\hline & G3 & 40 & 39.2 & 19 & 21 & \\
\hline \multirow[t]{2}{*}{ MIB1 } & $\leq 25$ & 73 & 71.6 & 28 & 45 & 0.087 \\
\hline & $>25$ & 24 & 23.5 & 14 & 10 & \\
\hline
\end{tabular}

ER, estrogen receptor; PgR, progesterone receptor; MIB1, monoclonal antibody against KI-67 protein; NS, not significant.

${ }^{a}$ Not all variables were measurable in all cases.

expression did not significantly correlate with tumor type, grade, size, steroid hormone receptor status, monoclonal antibody against $\mathrm{KI}-67$ protein (MIB1) reactivity, or patient age.

\section{Impact of T1-S on Disease-Free Survival}

Twenty-five of the 102 patients relapsed during the follow-up period (median 83 months). The prognostic 
impact of all factors on disease-free survival (DFS) was first determined by univariate Cox analysis (Table 2). Tumor type, size, steroid hormone receptor status, and age had no significant impact on DFS, whereas T1-S score ( $\leq 4$ vs $>4$ ), MIB1 ( $\leq 25 \%$ vs $>25 \%$ ), and tumor grade (G1 + G2 vs G3) did have a significant influence on DFS. Figures 2 and 3 show the DFS rates for the high- and low-risk groups as defined by T1-S and MIB1. Patients with high MIB1 proliferation index $(>25 \%)$ had a 3.7 -fold higher relapse risk than patients with low MIB1 ( $\leq 25 \%)$. Patients with high T1-S score $(>4)$ had a significantly reduced risk for relapse compared with patients with low T1-S score $(\leq 4)$ (Table 2).

In multivariate analysis, only the T1-S protein level and the MIB1 proliferation index had an independent, significant association with DFS. None of the other factors showed any additional impact on patient prognosis (Table 2).

\section{Discussion}

The biological significance of T1-S overexpression in human breast cancer is not yet well understood. Evidence has accumulated on T1-receptor function in the mouse, where $\mathrm{T} 1$ is expressed in proliferating osteoblastic precursor cells and the presence of $\mathrm{T} 1$ receptor is required in the differentiation of a mature osteoblast-producing bone matrix (Werenskiold et al, 1995, 1999). In the mouse mammary gland, T1-S is synthesized in the phase of tubular outgrowth in the pubertal female gland (Rössler et al, 1993), suggesting that T1-S also plays a role in the proliferation or differentiation of mammary epithelial cells. This is concordant with the observation that the highest level of T1-S mRNA in human breast cancer is expressed in ductal carcinomas and in particular in cells within

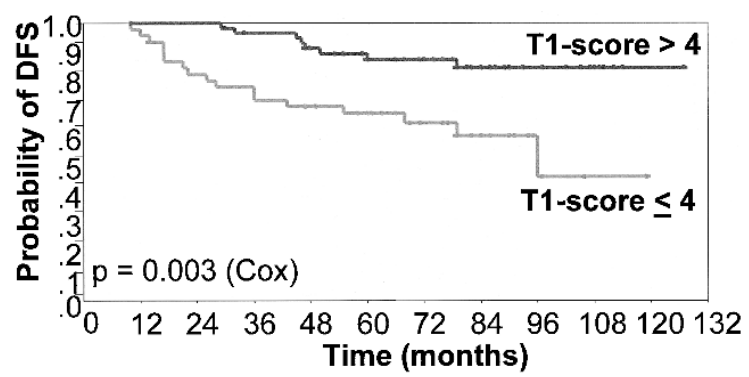

Figure 2.

Kaplan-Meier plot showing a significant impact of T1-S immunoreactivity on disease-free survival (DFS) in node-negative breast cancer. High T1-S scores $(>4 ; \mathrm{n}=58)$ are associated with longer DFS $(p=0.003)$ compared with low T1-S scores $(\leq 4 ; n=44)$.

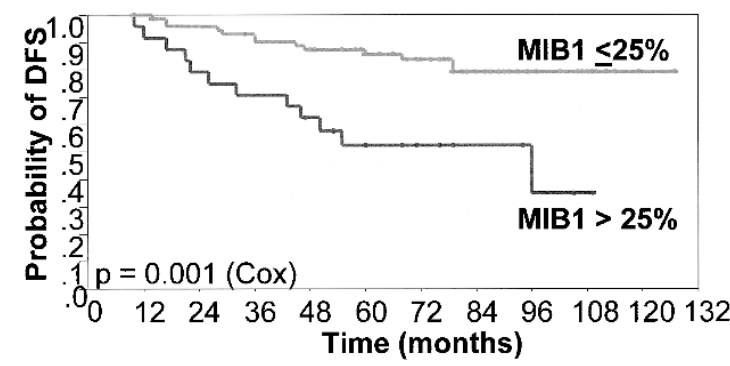

Figure 3.

Kaplan-Meier plot showing a significant impact of monoclonal antibody against $\mathrm{KI}-67$ protein (MIB1) immunoreactivity on DFS in node-negative breast cancer. Low MIB1 scores $(\leq 25 ; \mathrm{n}=73)$ are associated with longer DFS $(p=0.001)$ compared with high MIB1 scores $(>25 ; n=24)$.

tubular tumor areas (Werenskiold et al, 2000). This may indicate a correlation of T1-S synthesis with a differentiated epithelial phenotype. However, the lack of a correlation between the T1-S immunoreactivity score and the MIB1 proliferation index argues against

Table 2. Impact of Traditional and Tumor Biological Factors on DFS

\begin{tabular}{|c|c|c|c|c|c|}
\hline \multirow[b]{2}{*}{ Factor } & \multirow[b]{2}{*}{ Groups } & \multicolumn{2}{|c|}{ Univariate analysis } & \multicolumn{2}{|c|}{ Multivariate analysis } \\
\hline & & RR $(95 \%-C l)$ & $p$-value & RR $(95 \%-\mathrm{Cl})$ & $p$-value \\
\hline Age & $\begin{array}{l}\leq 60 \mathrm{yr} \\
>60 \mathrm{yr}\end{array}$ & $1.04(0.47-2.29)$ & NS & & NS \\
\hline ER & $\begin{array}{l}\text { Negative } \\
\text { Positive }\end{array}$ & $1.05(0.39-2.80)$ & NS & & NS \\
\hline $\mathrm{PgR}$ & $\begin{array}{l}\text { Negative } \\
\text { Positive }\end{array}$ & $0.85(0.37-1.97)$ & NS & & NS \\
\hline Tumor size & $\begin{array}{l}\leq 2 \mathrm{~cm} \\
>2 \mathrm{~cm}\end{array}$ & $1.71(0.74-3.95)$ & NS & & NS \\
\hline Tumor type & $\begin{array}{l}\text { Ductal } \\
\text { Lobular } \\
\text { Other }\end{array}$ & $\begin{array}{l}0.78(0.23-2.61) \\
0.45(0.06-3.35)\end{array}$ & NS & & NS \\
\hline Tumor grade & $\begin{array}{l}\mathrm{G} 1+\mathrm{G} 2 \\
\mathrm{G} 3\end{array}$ & $2.43(1.10-5.38)$ & 0.028 & & NS \\
\hline MIB1 & $\begin{array}{l}\leq 25 \\
>25\end{array}$ & $3.68(1.67-8.10)$ & 0.001 & $3.11(1.40-6.89)$ & 0.005 \\
\hline T1-S & $\begin{array}{l}\leq 4 \\
>4\end{array}$ & $0.28(0.12-0.65)$ & 0.003 & $0.32(0.14-0.75)$ & 0.009 \\
\hline
\end{tabular}

DFS, disease-free survival; $\mathrm{RR}$, relative risk; $\mathrm{Cl}$, confidence interval; NS, not significant/not selected. 
a proliferation-associated synthesis of T1-S in breast cancer cells.

Recent studies in mice have also implicated T1 in immune regulation. Membrane-associated $\mathrm{T} 1 \mathrm{recep}-$ tor is expressed in Th2 lymphocytes, and T1-S is capable of inhibiting Th2-cell-mediated immune responses to parasites (Lohning et al, 1998; Xu et al, 1998). Analogously, synthesis of T1-S in human breast cancer might affect the antitumor immune response in breast cancer patients. We therefore re-examined the node-negative breast cancer cases with respect to the presence of lymphocyte infiltrates. No correlation between the T1-S immunoreactivity score and evidence for an immune reaction was evident. Thus, the biological role of T1-S overexpression in human breast cancer remains unclear.

In our earlier small pilot study, we showed a correlation between tumor-associated T1-S mRNA levels and T1-S immunoreactivity in paraffin sections in a small collection of node-negative invasive breast carcinomas (Werenskiold et al, 2000). In the present study, we used immunohistochemistry to assess the tumor-biological role of T1-S in a larger, homogenous group of node-negative breast carcinomas. Because the majority of patients did not receive any adjuvant systemic therapy, the follow-up data reflects the natural course of the disease. The average age of the patients (59 yr), percentage of ductal carcinomas (78\%), hormone receptor status $(78 \%$ of the tumors were positive for estrogen receptor and $71 \%$ of tumors were positive for progesterone receptor), and MIB1 reactivity are all consistent with other studies of node-negative breast cancer patients (Dettmar et al, 1997; Oesterreich et al, 1996; Prechtel and Prechtel, 1993).

In our previous pilot study, which included 46 nodenegative breast carcinomas (Werenskiold et al, 2000), we found a correlation between tumor-associated T1-S mRNA levels and the tumor grade. In the present larger collection of 102 node-negative breast carcinomas analyzed by immunohistochemistry, we were not able to confirm this finding on the protein level. $\chi^{2}$ analysis found no association of the T1-S score with any other patient or tumor characteristics. The T1-S score was significantly associated with DFS in univariate and multivariate analyses, thus showing for the first time a correlation of T1-S expression with clinical outcome in node-negative breast cancer (high expression levels are correlated with a favorable prognosis). Of all other prognostic factors investigated in this study, only the MIB1 proliferation index and tumor grade were significantly associated with DFS in the univariate analysis. This is in agreement with published data (Dettmar et al, 1997; Gasparini et al, 1994; Sahin et al, 1991). In our study only MIB1 and not tumor grade remained a significant predictor for DFS using multivariate analysis. This may be partly due to the fact that MIB1 is the more precise measure of tumor cell proliferation, whereas the Bloom and Richardson grading system (Bässler et al, 1992), which is widely used in routine pathology, only gives a rough estimate of the percentage of mitotic tumor cells.
The above findings demonstrate for the first time that T1-S overexpression is a novel independent tumor-biological parameter associated with improved DFS. Further studies are needed to show whether T1-S is indeed functionally involved in the reduction of disease progression.

\section{Materials and Methods}

\section{Patient Population}

The study collective consisted of 102 female patients who underwent modified radical mastectomy $(n=65)$ or breast conserving therapy $(n=37)$ for primary breast cancer at the Department of Gynecology and Obstetrics, Technical University of Munich, between 1987 and 1993. Selection criteria for this study included the absence of axillary lymph node involvement and distant metastases. Ninety-four of these patients did not receive any adjuvant systemic therapy. At the time of surgery, the patients ranged in age from 37 to 82 years (median: $59 \mathrm{yr}$ ). The median length of survival of patients still alive at the time of analysis was 83 months (range: 48-126 mo). During follow-up, 25 patients $(25 \%)$ developed disease recurrence.

The tumors were staged according to the International Union Against Cancer tumor node metastasis (TNM) classification (Sobin and Fleming, 1997). Histological tumor grade $(\mathrm{G})$ was determined by a combined histological-cytological score (Bässler et al, 1992). Estrogen $(E R)$ and progesterone $(\mathrm{PgR})$ receptor expression was determined by immunohistochemistry and scored semiquantitatively (Remmele and Stegner, 1987). The proliferation marker MIB1 was determined by immunohistochemistry and scored according to the percentage of positive tumor cells (Dettmar et al, 1997).

\section{Antibodies and Immunohistochemistry}

The preparation and characterization of the antibodies and the immunohistochemistry method have been described (Werenskiold et al, 2000). In brief, the two antibodies used. (a) A rabbit polyclonal serum was raised against a synthetic peptide corresponding to the c-terminal sequence of the murine T1-S, which is specific for the T1-S variant of the T1 protein (Rössler et al, 1995). Purified immunoglobulin G ( $(g G)$ was used at a concentration of $13 \mu \mathrm{g} / \mathrm{ml}$. (b) The rat monoclonal antibody M144 was kindly provided by J. E. Sims of Immunex Corporation (Seattle, Washington). It was raised in rats against recombinant human T1-S-FC protein and cross-reacts with membrane-associated T1 receptor. It was used at a working concentration of $7 \mu \mathrm{g} / \mathrm{ml}$. Formalin-fixed, paraffin-embedded tissues from representative areas of the primary tumor were cut into 4- $\mu \mathrm{m}$ thick sections, deparaffinized, and hydrated. Slides were pretreated with $0.3 \% \mathrm{H}_{2} \mathrm{O}_{2}$ for 30 minutes to suppress endogenous peroxidase activity and incubated for 20 minutes with blocking serum. They were then incubated with antibodies against T1 for 12 hours at $4^{\circ} \mathrm{C}$. After washing, the specific color 
reaction was sequentially developed using the $A B C$ Vector Peroxidase staining kit (Camon, Wiesbaden, Germany).

Immunohistochemical T1-S reactivity was scored by two staff pathologists (DP and $\mathrm{HH}$ ) according to a modification of the method described by Remmele and Stegner (1987). By this method, two variables are determined. First, T1-S immunoreactivity is classified as absent (0), low (1), intermediate (2), or high (3). Secondly, the various percentages of $\mathrm{T} 1-\mathrm{S}$ reactive tumor cells classified by the following cut-off levels: $\geq$ $80 \%(4), \geq 50 \%$ (3), $>20 \%(2), \leq 20 \%$ (1), $0 \%(0)$. The T1-S immunoreactivity score is obtained as the product of these two variables and ranges from 0 to 12.

\section{Statistical Analyses}

The T1-S score was coded as a binary variable by employing log-rank statistics to determine an optimal cut-off (T1-S score $\leq 4$ vs T1-S score $>4$ ) for the discrimination of low- and high-risk patients. For traditional prognostic factors, binary coding was performed according to clinical conventions. Correlation of T1-S with the other factors was then evaluated using the $\chi^{2}$ Test of Independence.

Disease-free survival (DFS) rates were calculated using Kaplan-Meier estimates (Kaplan, 1958). The prognostic impact of all analyzed factors on DFS was assessed by Cox's Proportional Hazard Model (Cox, 1972) using the SPSS software package (SPSS Inc., Chicago, Illinois), which provides estimates of the relative risk $(\mathrm{RR})$ together with 95\% confidence intervals $(95 \%-\mathrm{Cl})$. To compare the prognostic power of various factors in multivariate Cox regression analysis, covariant selection was carried out by a stepwise forward procedure. The covariant selection obtained by the stepwise forward procedure was then validated by backward elimination analysis as well as by a model including all variables. Both of these methods confirmed the results obtained by the stepwise forward procedure. All tests were performed at a significance level of $\alpha=0.05$.

\section{Acknowledgements}

We are grateful to J. E. Sims for the generous gift of the anti-T1 monoclonal antibody 144 and to J. Mueller for critical reading of the manuscript.

\section{References}

American Cancer Society (1994). American Cancer Society National Conference on Breast Cancer, Boston, Massachusetts, August 26-28, 1993. Cancer 74:221-536.

Bässler R, Böcker W, Hermanek P, Pickartz H, Prechtel K, Schauer A, Schnurch HG, and Stegner HE (1992). [Current status of grading in breast cancer (see comments)]. Pathologe 13:130-134.

Bergers G, Reikerstorfer A, Braselmann S, Graninger P, and Buslinger $M$ (1994). Alternative promoter usage of the fosresponsive gene Fit-1 generates mRNA isoforms coding for either secreted or membrane-bound proteins related to the IL-1 receptor. EMBO J 13:1176-1188.

Clark GM and McGuire WL (1988). Steroid receptors and other prognostic factors in primary breast cancer. Semin Oncol 15:20-25.

Cox DR (1972). Regression models and life-tables. JR Stat Soc (B) 34:187-200.

DeMichele A and Weber BL (1997). Recent advances in breast cancer biology. Curr Opin Oncol 9:499-504.

Dettmar P, Harbeck N, Thomssen C, Pache L, Ziffer P, Fizi K, Jänicke $F$, Nathrath W, Schmitt M, Graeff $H$, and Höfler $H$ (1997). Prognostic impact of proliferation-associated factors MIB1 (Ki-67) and S-phase in node-negative breast cancer (see comments). Br J Cancer 75:1525-1533.

Gasparini G, Boracchi P, Verderio P, and Bevilacqua P (1994). Cell kinetics in human breast cancer: Comparison between the prognostic value of the cytofluorimetric $S$ phase fraction and that of the antibodies to Ki-67 and PCNA antigens detected by immunocytochemistry. Int $\mathrm{J}$ Cancer 57:822-829.

Hoskins K and Weber BL (1995). Recent advances in breast cancer biology. Curr Opin Oncol 7:495-500.

Kaplan EL (1958). Nonparametric estimation from incomplete observations. J Am Stat Assoc 53:457-481.

Klemenz R, Hoffmann S, and Werenskiold AK (1989). Serumand oncoprotein mediated induction of a gene with similarity to carcinoembrionic antigen. Proc Natl Acad Sci USA 86: 5708-5712.

Kumar S, Tzimas MN, Griswold DE, and Young PR (1997). Expression of ST2, an interleukin-1 receptor homolog, is induced by proinflammatory stimuli. Biochem Biophys Res Commun 235:474-478.

Lohning M, Stroehmann A, Coyle AJ, Grogan IL, Lin S, Guttierrez-RamosJC, Levinson D, Radbruch A, and Kamradt T (1998). T1/ST2 is preferentially expressed on murine Th2 cells, independent of interleukin 4, interleukin 5, and interleukin 10, and important for Th2 effector function. Proc Natl Acad Sci USA 95:6930-6935.

McGuire WL and Clark GM (1992). Prognostic factors and treatment decisions in axillary node negative breast cancer (see comments). N Engl J Med 326:1756-1761.

Merkel DE and Osborne CK (1989). Prognostic factors in breast cancer. Hematol Oncol Clin North Am 3:641-652.

Oesterreich S, Hilsenbeck SG, Ciocca DR, Allred DC, Clark GM, Chamness GC, Osborne CK, and Fuqua SA (1996). The small heat shock protein HSP27 is not an independent prognostic marker in axillary lymph node-negative breast cancer patients. Clin Cancer Res 2:1199-1206.

Porter PL, Malone KL, Heagerty PJ, Alexander GM, Gatti LA, Firpo EJ, Daling JR, and Roberts JM (1997). Expression of cell-cycle regulators p27kip1 and cyclinE, alone and in combination, correlation with survival in young breast cancer patients. Nat Med 3:222-225.

Prechtel D and Prechtel K (1993). [Quantitative determination of steroid hormone receptors in breast cancer tissue outside tumor centers]. Pathologe 14:16-20.

Remmele W and Stegner HE (1987). [Recommendation for uniform definition of an immunoreactive score (IRS) for immunohistochemical estrogen receptor detection (ER-ICA) in breast cancer tissue]. Pathologe 8:138-140. 
Rössler U, Andres AC, Reichmann E, Schmahl W, and Werenskiold AK (1993). T1, an immunoglobulin superfamily member, is expressed in $\mathrm{H}$-ras-dependent epithelial tumours of mammary cells. Oncogene 8:609-617.

Rössler U, Thomassen E, Hultner L, Baier S, Danescu J, and Werenskiold AK (1995). Secreted and membrane-bound isoforms of $\mathrm{T} 1$, an orphan receptor related to IL-1 binding proteins, are differently expressed in vivo. Dev Biol 168:8697.

Sahin AA, Ro J, Ro JY, Blick MB, el-Naggar AK, Ordonez NG, Fritsche HA, SmithTL, Hortolobagyi GN, and Ayala AG (1991). Ki-67 immunostaining in node-negative stagel/II breast carcinoma. Significant correlation with prognosis. Cancer 68:549-557.

Silvestrini R, Benini E, Veneroni S, Daidone MG, Tomasic G, and Salvadori B (1996). p53 und bcl-2 expression correlates with clinical outcome in a series of node-negative breast cancer patients. J Clin Oncol 14:1604-1610.

Sobin LH and Fleming ID (1997). TNM Classification of Malignant Tumors, fifth edition (1997). Union Internationale Contre le Cancer and the American Joint Committee on Cancer. Cancer 80:1803-1804.

Soong R, lacopetta BJ, Harvey JM, Serrett GF, Dawkins HJ, Hahnel R, and Robbins PD (1997). Detection of p53 gene mutation by rapid PCR-SSCP and its association with poor survival in breast cancer. Int J Cancer 74:642-647.
Thomassen E, Kothny G, Haas S, Danescu J, Hültner I, Dörmer P, and Werenskiold AK (1995). Role of celltypespecific promoters in the developmental regulation of $\mathrm{T} 1$, an Interleukin-1 receptor homologue. Cell Growth Differ 6:178184.

Tominaga S, Yokota T, Yanagisawa K, Tsukamoto T, Tagaki T, and Tetsuka T (1992). Nucleotide sequence of a complementary DNA for human ST2. Biochim Biophys Acta 1171: 215-218.

Werenskiold AK, Prechtel D, Harbeck N, and Höfler H (2000). Tumor-associated overexpression of the soluble T1-S receptor in lymph node-negative breast cancer. Diagn Mol Pathol 9:26-34.

Werenskiold AK, Rössler U, Löwel M, Schmidt J, Heermeier K, Spanner MT, and Strauss PG (1995). Bone matrix deposition of $\mathrm{T} 1$, a homologue of interleukin 1 receptors. Cell Growth Differ 6:171-177.

Werenskiold AK, Schmidt J, Rupp B, Gossner W, and Höfler $H$ (1999). Suppression of T1 receptor expression by antisense RNA abrogates differentiation of osteogenic osteosarcoma cells. Lab Invest 79:529-536.

Xu D, Chan WL, Leung BP, Hunter D, Schulz K, Carter RW, Mclnnes IB, Robinson JH, and Liew FY (1998). Selective expression of a stable cell surface molecule on type 2 but not type 1 helper T cells. J Exp Med 187:787-794. 